\title{
Discussion aspects of determining the list of means and techniques of legislative technique in the law-making process
}

\author{
O. G. Solovyev ${ }^{1}$, Yu. O. Goncharova ${ }^{1}$
}

${ }^{1}$ P. G. Demidov Yaroslavl State University, 14 Sovetskaya str., Yaroslavl 150003, Russian Federation

DOI: 10.18255/1996-5648-2021-1-76-83

Research article

Full text in Russian

The article examines the means and techniques of legislative technique as the main primary components of the construction of legal norms, the authors explore the controversial aspects of determining the range of key technical and legal instruments. The authors note the negative aspects in the process of using the tools and techniques of legislative technique in the regulation of criminal law prohibitions.

The main technical and legal problems in modern criminal law-making are the unjustified casuistification of dispositions of normative prescriptions, the bulkiness of criminal law prohibitions. In some cases, the volume (capacity) of individual dispositions exceeds 150 words. Such normative decisions significantly complicate the perception of elements of a crime, complicate the assessment and comparison of the committed act with a specific criminal norm. These circumstances negatively affect the qualification process and do not meet the needs of law enforcement practice.

Certain gaps are observed in the construction of blank dispositions, in a situation where the legislator uses significant prescriptions borrowed from normative acts of other branches of law in the description of encroachments. The paper also notes, that the rules of legislative technique do not relate to basic structural elements, since they are auxiliary (secondary) components of the legislative process and are already associated with the use of tools and techniques in the course of practical normative design, formation of specific legal prescriptions.

Keywords: legislative technique; law-making process; tools; means; techniques; legal constructions; linguistic means; definitions; notes; legal symbols; presumptions; fictions

\section{INFORMATION ABOUT AUTHORS}

\author{
Soloviev Oleg G. | E-mail: olegsol1961@yandex.ru \\ Cand. Sc. (Jurisprudence), Associate Professor \\ \begin{tabular}{l|l} 
Goncharova Yulia O. & $\begin{array}{l}\text { E-mail: julygoncharova97@yandex.ru } \\
\text { Postgraduate student }\end{array}$
\end{tabular}
}

(c) Soloviev O. G., Goncharova Yu. O., 2021

This is an open access article under the CC BY license (https://creativecommons.org/licenses/by/4.0/) 


\title{
Дискуссионные аспекты определения перечня средств и приемов законодательной техники в правотворческом процессе
}

\author{
О. Г. Соловьев ${ }^{1}$, Ю. О. Гончарова ${ }^{1}$
}

${ }_{1}^{1}$ Ярославский государственный университет им. П. Г. Демидова, ул. Советская, 14, Ярославль, 150003, Российская Федерация

DOI: $10.18255 / 1996-5648-2021-1-76-83$

УДК 340.1

Научная статья

В статье рассматриваются средства и приемы законодательной техники как основные первичные компоненты конструирования правовых норм, исследуются дискуссионные аспекты определения круга ключевых технико-юридических инструментов. Авторы отмечают негативные аспекты в процессе использования средств и приемов законодательной техники при регламентации уголовно-правовых запретов.

Основными технико-юридическими проблемами в современном уголовном правотворчестве является необоснованная казуистифрикация диспозиций нормативных предписаний, громоздкость уголовно-правовых запретов. В некоторых случаях объем (емкость) отдельных диспозиций превышает 150 слов. Такие нормативные решения значительно затрудняют восприятие признаков состава преступления, усложняют оценку и сопоставление совершенного деяния с конкретной криминальной нормой. Указанные обстоятельства негативно влияют на процесс квалификации и не соответствуют потребностям правоприменительной практики.

Определенные пробелы наблюдаются в конструировании бланкетных диспозиций, в ситуации когда законодатель использует в обрисовке посягательства значительные по объему предписания, заимствованные в нормативных актах иных отраслей права. В работе также отмечается, что правила законодательной техники не относятся к базовым конструктивным элементам, поскольку они являются вспомогательными (вторичными) составляющими законотворческого процесса и связаны уже с применением средств и приемов в ходе практического нормативного конструирования, формирования конкретных юридических предписаний.

Ключевые слова: законодательная техника; правотворческий процесс; инструменты; средства; приемы; юридические конструкции; лингвистические средства; деоиниции; примечания; правовые символы; презумпции; фрикции

\section{ИНФОРМАЦИЯ ОБ АВТОРАХ}

\begin{tabular}{c|l} 
Соловьев Олег Геннадиевич & $\begin{array}{l}\text { E-mail: olegsol1961@yandex.ru } \\
\text { Кандидат юридических наук, доцент }\end{array}$ \\
Гончарова Юлия Олеговна & $\begin{array}{l}\text { E-mail: julygoncharova97@yandex.ru } \\
\text { Аспирант }\end{array}$
\end{tabular}

(C) Соловьев О. Г., Гончарова Ю. О., 2021

Статья открытого доступа под лицензией CC BY (https://creativecommons.org/licenses/by/4.0/) 
Соловьев О. Г., Гончарова Ю. О.

В последние годы внимание научной общественности и представителей правоприменительной практики к проблемам законодательной техники в уголовном праве по непонятным причинам резко снизилось. По сути, в настоящее время специальными вопросами использования технико-юридических средств в конструировании норм уголовного закона занимаются в основном представители ярославской и нижегородской правовых школ. Причинами подобного положения вещей, на наш взгляд, являются отсутствие внимания к полученным научным результатам со стороны представителей законодательной власти, незначительный учет рекомендаций теории законодательной техники в правотворческом процессе, сосредоточение внимания правоприменительной практики на проблемах квалификации криминальной деятельности, оценки и анализа действующего закона, а не на вопросах его нормативного исправления, позитивной реконструкции. В результате наблюдается очевидная тенденция ухудшения качества уголовного законодательства как в части нормативных новелл, так и в части реконструкции ранее действующего законодательства. Это прежде всего выражается в нарушении системности закона, его усложнении, необоснованной казуистификации, росте противоречий с бланкетным законодательством. Учитывая изложенное, считаем актуальным и полезным обращение в данной статье к исследованию технико-юридического инструментария законодательного конструирования.

В теории права принято считать, что основные компоненты (приемы и средства) законодательной техники представляют собой нематериальные инструменты, используемые при создании закона. Проблемой выявления и определения круга таких элементов занимались различные ученые-правоведы, к примеру, В. К. Бабаев, Е. В. Ильюк, С. С. Алексеев, Л. Л. Кругликов, А. В. Иванчин, Ю. А. Тихомиров и др. Попытаемся определить необходимые структурные элементы законодательной техники, которые образуют ее функциональное содержание. Очевидно, что указанный процесс затрудняют многогранность и противоречивость исследуемого нами феномена законодательной (юридической) техники.

Большинство специалистов причисляют к основным инструментам конструирования правовой нормы технико-юридические приемы и средства; при этом средства являются субстанциональным стержнем законодательной техники и поэтому первичны по отношению к приемам (методам, способам) [1, с. 36]. В свою очередь, правила, по описанию правоведов, «характеризуют использование технических средств и приемов, относящихся в основном к внешней фрорме» [2, с. 121]. Отсюда следует, что более точную и аргументированную позицию занимают специалисты, которые фрормулируют понятие законодательной техники как сопряжение технико-юридических компонентов (приемов и средств) в целях создания и формирования соответствующего нормативного материала, адекватно отражающего волю законодателя [2, с. $120 ; 3$, с. 101]. 
Действительно, указанное определение содержательно, экономно и вычленяет базовые стратегические составляющие исследуемого понятия. Именно указанный инструментарий законодательной техники будет нами рассмотрен далее.

Тем не менее, как уже говорилось, четкого определения круга и юридического содержания инструментов законодательной техники в доктрине не наблюдается. Постараемся кратко обрисовать нашу позицию по этому вопросу, поскольку содержательные характеристики технико-юридических инструментов целесообразнее подробно рассматривать в процессе анализа конкретных уголовно-правовых запретов либо группы таких запретов.

Остановимся на перечне и техническом значении приемов законодательной техники. Так., А. В. Иванчин определяет приемы как «способы построения нормативных предписаний, в том числе соединенные с использованием определенного средства» [4, с. 25]. К последним ученый причисляет: дефиниции (определения, термины), непосредственно-определенный и ссылочный приемы, прием примечания. Как видно, автор относит построение бланкетных диспозиций нормы по способу изложения к ссылочному приему. Мы считаем, что это несколько смешивает основания содержательного разграничения приемов конструирования нормы. Достаточно часто мы можем наблюдать, что в доктринальных исследованиях смешиваются такие технические компоненты, как приемы и средства. Причин подобного явления множество. Так, А. Нашиц причисляет к технико-юридическим приемам (называя их приемами правовой типизации) определения, классиорикации, юридические конструкции, презумпции, фрикции [5, с. 193]. Мы не склонны поддерживать такую позицию, поскольку, к примеру, юридические конструкции не относятся к абстрактным механизмам правотворчества, а являются конкретной нематериальной фрормой, которую наполняют лингвистическим нормативным содержанием.

Иные правоведы определяют две категории (группы) исследуемых технических инструментов: 1) по способу изложения - бланкетный, ссылочный, прямой; 2) по степени обобщения конкретных показателей - абстрактный и казуистический (в отдельных случаях - смешанный) [6, с. 121; 7, с. 297]. Полагаем, что указанную точку зрения надо рассматривать в совокупности и в этом случае возможно выработать комплексный вариант определения и вычленения приемов законодательной техники из общей группы технических компонентов. Так, к приемам законодательной техники необходимо отнести: 1) абстрактный и казуистический (по степени обобщения конкретных показателей нормы); 2) непосредственно-определенный (прямой), ссылочный и бланкетный (по способу изложения); 3) прием - примечание; 4) прием - дефиниция [7, с. 299].

Далее рассмотрим перечень средств законодательной техники и краткое их содержание. В доктрине уголовного права справедливо указывается, что «под средствами правовой техники должны пониматься не явления 
Соловьев О. Г., Гончарова Ю. О.

или методы (способы), a sui generis нематериальные инструменты законодателя [8, с. 64]. Необходимо отметить, что в современной правовой доктрине также не существует единой позиции в отношении перечня указанных средств. Как и в ситуации с приемами, ученые и практические специалисты порой смешивают средства с иными инструментами законодательной техники, о чем мы говорили выше.

В иных ситуациях привносят в число средств инструменты, по сути не относящиеся к содержательным техническим элементам, способным непосредственно участвовать в содержательном оформлении нормативного материала. В качестве примера можно привести такой вариант: а) средства юридического выражения воли законодателя, к которым следует относить нормативные построения; б) средства словесно-документального выражения текста: реквизиты, структурные построения, юридическую терминологию. Кроме этого, к ним автор причисляет аксиомы, символы, юридические конструкции, презумпции, фрикции [9, с. 120]. Полагаем, что нормативное построение, по сути, и является юридической конструкцией. Реквизиты же вообще не относятся к содержательным элементам нормативной техники. Скорее, являются оформительско-процедурным элементом нормативного правового акта и никак не влияют на реализацию правовых механизмов, закрепленных в данном акте.

В свою очередь, по мнению С. С. Алексеева, к средствам законодательной техники относятся: а) средства изложения воли законодателя - нормативное предписание, юридическая конструкция, отраслевая типизация, юридическая терминология; б) средства документального выражения - документы или реквизиты, внутреннее строение, а также законодательная стилистика [6, с. 268]. Полагаем, что некоторые из указанных элементов сложно отнести к средствам построения закона (в том числе и уголовного), поскольку они не имеют функционального стратегического значения, а являются вторичными (факультативными) инструментами изложения и закрепления воли законодателя.

Учитывая изложенное, справедливым считаем мнение, что применительно к современному уровню общей теории российского права имеются основания оперировать в науке уголовного права следующими понятиями: а) юридическая конструкция, б) юридическая терминология (язык закона), в) презумпция и аксиома, г) фрикция, д) правовой символ.

Повторимся, что в данный перечень мы включаем исключительно базовые, ключевые нормативные технические компоненты, без которых невозможно осуществление законотворческого процесса применительно к любой отрасли права. При этом вряд ли возможно считать указанный выше перечень конечным, отражающим исключительный набор технико-юридических правотворческих инструментов. Позиция о дальнейшем развитии инструментария юридической техники, расширении и обновлении перечня ее основных и фракультативных элементов активно поддерживается многи- 
ми учеными и практическими работниками. Так, Л. Л. Кругликов верно замечает, что «по мере развития теории будут вычленены и иные средства как уже фактически используемые законодателем, так и могущие быть использованными для нормативного закрепления, юридического выражения воли законодателя» [10, с. 61].

Если же говорить о правилах законодательной техники, наша позиция, напомним, заключается в том, что последние сопряжены исключительно с внешней оболочкой (формой) правовой материи и связаны с применением перечисленных выше средств и приемов уже в процессе реального нормативного конструирования. Например, использование правил правовой лингвистики при использовании языковых средств: предложений, терминов и т. д. В юридической литературе справедливо указывается, что правила являются вторичными (производными, фракультативными) компонентами законодательной техники по отношению к основным средствам и приемам [11, с. 89]. Их вторичность (фракультативность) определяется вспомогательным назначением, необходимостью регулировать использование средств и приемов. По этой причине мы также не считаем правила законодательной техники самостоятельным инструментом. Именно сложившийся набор технико-юридических приемов и средств диктует фрормирование правил, делает их зависимыми от основных нормотворческих инструментов. Так, можно выделить правила синтаксиса, морфологии, экономии нормативного материала, общелингвистические, стилистические, логические и другие правила. Общелингвистические правила, которые наиболее часто нарушаются в процессе технико-юридического конструирования, непосредственно связаны с разработкой основных предписаний, требования и положений требований, связанных с использованием языковых инструментов в процессе изложения нормативного материала, в том числе правовой (законодательной, интерпретационной, правоприменительной) терминологии. $\mathfrak{K}$ таковым можно отнести технико-юридические условия по ясности языка, конкретности, отраслевой принадлежности, краткости (лаконичности), точности.

Следовательно, нет необходимости определять технико-юридические правила как ключевые (основные) инструменты законодательной техники. На наш взгляд, они являются вспомогательным компонентом, своеобразным вектором (направлением), который предлагает законодателю способы эфрективного и адекватного применения в законотворческом процессе необходимых средств и приемов. Действительно, учитывая то, что ранее обосновывалась позиция о вспомогательном (вторичном) значении технико-юридических правил по отношению к базовым, упомянутым выше инструментам (средствам и приемам), встает вопрос, стоит ли рассматривать правила как обязательный элемент законодательной техники и закреплять это понятие в определении законодательной техники. Представляется, что такое решение будет неоправданным и излишним. Стоит заметить, 
что указанное обстоятельство повлияло на то, что технико-юридические правила не стали предметом самостоятельного исследования в доктрине уголовного права по проблемам техники регламентации преступных посягательств и иных уголовно-правовых предписаний. В большинстве случаев правила фракультативно исследуются учеными-правоведами при анализе ключевых элементов законодательной техники.

Основным и необходимым средством законодательной техники следует считать язык уголовного закона. То, в какой фрорме будет изложено содержание нормы, зависит от особенностей стиля, который присущ правовым актам. Из официально-делового стиля вытекает особая терминология и, соответственно, то, какие в норме будут использованы синтаксические, терминологические и лексические средства. В правотворческой практике выделяют несколько общих требований к лингвистике правового акта: логичность, профессиональность, нейтральность, точность, лаконичность и т. д.

Для того чтобы текст нормы было легче воспринимать, а это иногда особенно трудно из-за обширности той или иной нормы, законодателю следует придерживаться требований лаконичности и компактности, т.е. необходимо экономно в разумных пределах использовать языковой материал при создании нормы. Данные требования логично вытекают из требований точности и простоты изложения правовых предписаний. На наш взгляд, избранная норма соответствует данным требованиям, диспозиция сорормулирована кратко и доступно.

Особое место в ряду средств законодательной техники занимают юридические конструкции. Поскольку, на наш взгляд, выбор соответствующей конструкции и является началом содержательного этапа создания нормативного предписания, ошибки на этом этапе создания правовых предписаний могут привести к очевидным пробелам и противоречиям в создаваемом законе. Стремясь облегчить и упростить конструирование правовых норм, законодатель использует прежде всего указанный технический инструмент, так как это придает юридической регламентации общественных отношений стройность, лаконичность, определенность, строгость и четкость.

В данном случае особое внимание хотелось бы уделить фрормулированию диспозиций норм. От полноты и качества изложения диспозиции во многом зависит то, как эта норма будет работать на практике.

Характеризуя такие средства, как презумпции, фрикции и аксиомы, следует отметить, что они имеют общее конструктивное начало: отражают уже установленные знания и потому могут использоваться в качестве отправной точки для создания новых, толкования уже существующих норм $[11$, с. 125]. По большей части перечисленные компоненты используются в предписаниях Общей части уголовного кодекса и, следует заметить, практически оставлены без внимания отечественной уголовно-правовой доктриной. Единственным прорывом в этой части является диссертационное 
исследование представителя ярославской юридической школы Ю. Г. Зуева, подготовленное 20 лет назад и посвященное анализу презумпций в уголовном праве [12].

Еще одним не менее важным средством законодательной техники выступает символ. По общему мнению, правовые символы представляют собой закрепленные законодательством условные образы, используемые для выражения определенного содержания. В уголовном праве символы играют существенное значение в вопросах сокращения нормативного материала, играя, по сути, роль бланкетного признака, акцентируют внимание правоприменителя на объекте и предмете преступного посягательства. В отдельных случаях символы имеют дифференцирующее содержание.

\section{Ссылки}

1. Кругликов Л. Л., Соловьев О. Г. Преступления в сфере экономической деятельности и налогообложения: вопросы конструирования составов и дифференциации ответственности). Ярославль: ЯрГУ, 2003. 224 с.

2. Алексеев С. С. Государство и право: учебное пособие. М.: Проспект, 2015. $152 \mathrm{c}$.

3. Законодательная техника: научно-практическое пособие / Л.Ф.Апт, Н. А. Власенко, В. Б Исаков [и др.]; под ред. Ю. А. Тихомирова. М.: Городец, 2000. 272 c.

4. Иванчин А. В. Уголовно-правовые конструкции и их роль в построении уголовного законодательства: авторефр. дис. ... канд. юрид. наук. Екатеринбург, 2003. $24 \mathrm{c}$.

5. Нашиц А. Правотворчество: Теория и законодательная техника / пер. с румынского И. Фодор; под ред. Д. А. Керимова, А. В. Мицкевича. М.: Прогресс, 1974. 256 c.

6. Алексеев С. С. Теория государства и права. М.: Норма, 2004. 283 с.

7. Панько К. К. Правила и приемы российского уголовного законотворчества // Lex russica. 2014. № 3. C. 294-304.

8. Иванчин А. В. Факторы, учитываемые в процессе конструирования состава преступления // Вестник ЯрГУ. Серия Гуманитарные науки. 2015. № 2 (32). С. 61-65.

9. Бабаев В. К. Теория государства и права: учебник / под ред. В. К. Бабаева. М.: Юристъ, 2003. 592 с.

10. Кругликов Л. Л. Квалисрицирующие признаки как средство дифференциации уголовной ответственности: современное состояние // Вестник Ярославского государственного университета им. П.Г.Демидова. Серия Гуманитарные науки. 2007. № 4. С. 56-64.

11. Иванчин А. В. Концептуальные основы конструирования состава преступления: дис. ... д-ра юрид. наук. Екатеринбург, 2015. 462 с.

12. Зуев Ю. Г. Презумпции в уголовном праве: дис. ... канд. юрид. наук. Казань, 2000. $201 \mathrm{c}$. 